\title{
Metaphorical Blends (Case Study of Metaphorization of Concept BOOK)
}

\author{
Natalia Berezhnykh ${ }^{1}$, Natalia Sivtseva ${ }^{2 *}$, Tatiana Skopintseva ${ }^{1}$, and Assia Kontrimovich ${ }^{1}$ \\ ${ }^{1}$ Irkutsk State Transport University, Department of Foreign Languages, 664074 Irkutsk, Russia \\ ${ }^{2}$ Irkutsk National Research Technical University, Department of Applied Linguistics, 664074 Irkutsk, Russia
}

\begin{abstract}
The article deals with the mechanism of creating metaphor in the context of the theory of conceptual integration. A particular emphasis is laid on the basic theses of the theory of conceptual metaphor and the theory of conceptual integration. The comparison of G. Lakoff and M. Johnson's theory of conceptual metaphor and G. Fauconnier and M. Turner's theory of conceptual integration is carried out. The analysis of the examples of metaphorical mapping of the concept BOOK is conducted and three conceptual metaphors of the given concept (the target domain) are defined. Each conceptual metaphor is described, the input spaces, generic and blended spaces are defined. The integrated roles and emergent properties and structures are determined and explained.
\end{abstract}

\section{Introduction}

Currently, metaphor is researched within the scope of the cognitive linguistics and is regarded as a means of expressing some new knowledge. It is necessary to underline and prove that metaphor is one of the means of the linguistic creativity, and the best way to do this is to apply the methods of the theory of conceptual integration to the metaphor studies. The original research supports and develops O. Iriskhanova's idea that the characteristics of conceptual integration present the underlying mechanism of the linguistic creative activity which is understood as the human ability to build and integrate different mental constructions in the situation of verbal communication in an inventive manner [1].

In the given article, we use the theory of conceptual integration as a theoretical background of the metaphor study as it helps to regard this phenomenon in a new way. Metaphor is studied in the context of two aspects: static (as a result) and dynamic (as a process). The static method allows describing the result of the completed process of metaphorization in the language picture of the world. The dynamic aspect allows studying the very mechanism of creating the metaphor and some new unique meaning that appears every time "here and there".

\section{The theory of conceptual metaphor vs the theory of conceptual integration}

The theory of conceptual metaphor by G. Lakoff and M. Johnson presents the static aspect of metaphor. This theory was observed for the first time in the book "Metaphors We Live By" in 1980 [2]; a lot of linguists were interested in it and tried to develop and prove the main statements of the theory in their scientific works [3, $4,5,6]$. According to the theory, metaphor is a linguistic phenomenon reflecting the process of cognition and the metaphorical models existing in the conceptual system of a human being are schemes that form the human process of thinking and acting.

Traditionally, the previous studies regarded metaphor from the point of view of linguistic form (applying the linguistic unit to some new unusual denotation) and used it as a means of linguistic finery helping to implement the poetic function of the language. However, J. Lakoff and M. Johnson defined metaphor as a characteristic feature of the human thought; they wrote that metaphor penetrated all spheres of the human life as well as thought, activity and so on, because the human conceptual system had a metaphorical nature [2].

In their scientific works they draw a line between the linguistic means of representing metaphor and the cognitive process creating its basis; they also underline the idea that not an isolated linguistic unit (with its usual nominative meaning) undergoes the process of metaphorical shift but the whole conceptual structure (scheme, frame, model, scenario). At this stage, the metaphorical or cognitive mapping occurs, that is, the knowledge of one conceptual field is reflected in another conceptual field. Thus, the knowledge structures from the source domain are transferred to the target domain. The result of the interaction of these cognitive structures is the interpretation of one object or phenomenon in the context of another object or phenomenon on the basis of their common features. The source domain is more concrete knowledge obtained, as a rule, via the direct physical experience. So, the conceptual metaphor IDEAS ARE FOOD, according to the given theory, allows understanding the psychological processes that

* Corresponding author: s_nataly77@mail.ru 
cannot be explained through the direct and obvious conceptualization. This metaphor shows that ideas as well as food can be swallowed, warmed up, digested and so on. The concept BOOK is also interpreted by the English native speakers with the help of the metaphor A BOOK IS FOOD:

...he had let Jack pick out the books he read for free - choice book reports, not caring what they were, chewing them up as if they were cereal (King S., The Talisman);

She had swallowed the textbook (Rowling J.K., Harry Potter and the Chamber of Secrets).

The given metaphor is based on the similarities between food and books: the book content as well as food can whet the appetite, it can be chewed, swallowed etc. A human being has some knowledge of the processes of swallowing, chewing and digesting, and this knowledge was obtained directly on the basis of the physical experience. Then he/she applies this knowledge to the process of taking in some new ideas or book content creating the metaphor.

G. Lakoff and M. Johnson define various types of conceptual metaphors forming the linguistic and conceptual pictures of the English-speaking community (ARGUMENT IS WAR, UNDERSTANDING IS SEEING, LIFE IS A JOURNEY etc.) and consider the conceptual metaphor as a fundamental cognitive operation that is responsible for the mapping of frames from one conceptual field to another. They determine three overlapping types of conceptual metaphors:

1. Structural metaphors structure one knowledge area with the help of the structure of another area. G. Lakoff and M. Johnson state that if war and argument are described in the same terms and words (ARGUMENT IS WAR), it means that they are interpreted and perceived in the same way. It happens because the human knowledge about the argument and the way of its conducting is based on our experience of physical collision [2, 256].

2. Orientational metaphors allow building new knowledge with the help of spatial concepts and relations: "up - down", "forward - backward" etc. Thus, in the English language the concepts HAPPINESS, HEALTH are described via the metaphor UP, whereas UNHAPPINESS, ILLNESS - via the metaphor DOWN.

3. Ontological metaphors help to understand the abstract phenomena (feelings, ideas, emotions, actions, events) as physical objects with their usual characteristic features: LOVE IS A PATIENT, INFORMATION IS LIQUID etc.

Lakoff and Johnson's theory reveals the modelling function of metaphor which means that metaphor does not only form the notion of an object but predetermines the way of thinking about it. As a result, the new knowledge is conceptualized similarly to the existing conceptual system [7]. However, the theory of conceptual metaphor does not give a clear answer to the following question: How does the process of interaction between the cognitive source domain and the target domain occur directly in the discourse? This question is answered, perhaps, in the context of the theory of conceptual integration.
The theory of conceptual integration developed by Gilles Fauconnier and Mark Turner that became very popular and widely used in the foreign linguistic studies is one of the cognitive linguistics directions investigating the ways and means of constructing the linguistic meaning. In the context of this theory, the production and perception of the discourse are treated as the process of the sequential deployment of the mental spaces [8]. According to G. Fauconnier's conception, mental spaces are considered as small conceptual areas (packets), which are built during the processes of thinking and speaking and the aim of their creation is local understanding and action $[9,10,11]$. Within the scope of the theory of mental spaces, the linguistic constructions are represented as instructions that allow producing some mental framing of the real, hypothetic or imaginary situations (plots of books, films etc.). Consequently, mental space is not some abstract domain, it is a scenario of the definite situation and a model of the discursive understanding. Mental spaces are created and changed during the very process of communication and they are characterized by the great degree of flexibility. This very property reflects the peculiarities of the human communication and allows modelling the process of speech perception in a more appropriate way.

Mental spaces are of cognitive nature, thus, they do not have any ontological status out of the bounds of the human consciousness. They are structured by frames and cognitive models that are kept in the long-term memory, whereas the area of their functioning is short-time (working) memory. In the latter type of memory, the mental spaces are constructed and changed together with the changes of the thought and the development of the discourse. In addition, one mental space can be constructed by the means of the knowledge that refers to different conceptual domains. For example, the mental space in which my father's next door buying my books may involve the knowledge referring to such conceptual spaces as reading, buying and selling, social conversation in public places etc.

According to Fauconnier's theory [11], as it was mentioned above, mental spaces are created in the shorttime memory, but they can be rooted in the long-time memory as well. For instance, frames are mental spaces that are kept in the long-time memory and can be activated simultaneously. In the discourse, the frames are filled with definite roles and values of the objects. So, in the utterance His school books were very interesting the role of "school books" becomes definite due to the value "very interesting".

During the process of production and perception of the discourse, these constantly changing mental spaces can be interrelated by different types of links: temporal, spatial, hypothetic, identifying, counter-factual, causative, analogical or metaphorical mapping, metonymical interference etc. These various links combine the mental spaces into flexible systems and open the full access to the whole body of spaces allowing the speakers to make all necessary changes in any moment.

Analyzing different types of interaction between the mental spaces, G. Fauconnier transformed the theory of 
mental spaces into the theory of conceptual integration that is regarded as an underlying semantic process. This theory is developed by G. Fauconnier and one of the American literary scholars M. Turner [10, 11]. Nowadays the process and result of blending mental spaces are studied in various layers of linguistic and nonlinguistic phenomena: semantics of lexical units, syntactic constructions, grammatical units, idioms, fiction structure, advertisement, different stylistic means, humour, emotions, conceptualization, categorization, metaphor, metonymy etc. Blending of mental spaces that was originally regarded as a separate cognitive operation became one of the principles of general cognition - the principle of conceptual integration ("Blending is everywhere!"). A great many of American cognitive scholars endow the production of integrated spaces with the status of the underlying operation that can explain and reveal the nature of all cognitive processes [8].

The conceptual integration is defined by the authors as a basic cognitive operation forming the human ability to speculate, to reason, to induce, to estimate, to make decisions and inventions, etc.; this operation is dynamic and flexible and it is conducted swiftly and unconsciously [12]. During the discourse development the integrated spaces (blends) being the result of mental spaces blending are created (the term "blend" is analyzed in scientific works by E. Rakhilina [13]. These integrated spaces being an undivided structural whole allow reconstructing their relations with original mental spaces.

It should be mentioned that in contrast to the theory of conceptual metaphor presenting the general interpretation of metaphorization, the theory of conceptual integration allows carrying out deeper and more detailed analysis of the metaphorical process. The essence of metaphor in the context of the given theory is as follows: during the development of the discourse new integrated spaces (blends) appear as a result of merging of mental spaces. G. Fauconnier and M. Turner usually demonstrate the integration process in a graphic form (Fig. 1).

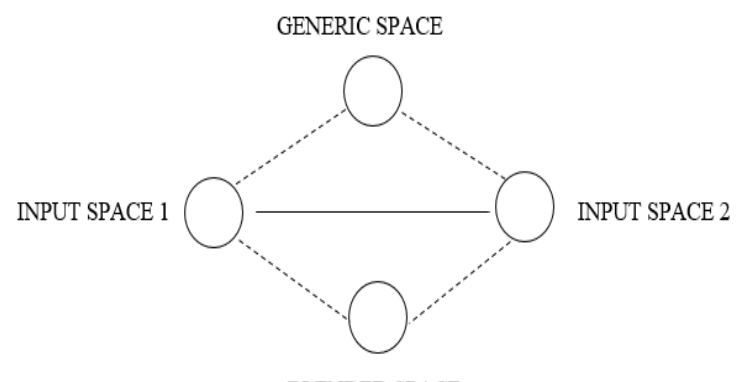

BLENDED SPACE

Fig. 1. The Integration Process.

Thus, this scheme shows the interaction of four mental spaces: two input spaces, a generic space that is formed by the structure that is close to the input spaces and a blended space. The solid line represents the crossspatial reflection and the dotted lines - the selective mapping. The created blend develops its own structure and is not identical to input mental spaces, moreover, its meaning cannot be defined as a sum of the input spaces meanings, it inherits only some characteristics of the original mental spaces. So, G. Fauconnier introduces such example - This surgeon is a butcher. This sentence is a real blend of two original spaces: the space of "surgeon" and the space of "butcher". Due to this integration, the metaphorical blend gets the new property - "incompetence". This method allows analyzing the following example:

Nature to him was an open book whose letters he could read without effort (The British National Corpus).

This utterance is a blend created as a result of mapping of two original spaces: the space of "nature" and the space of "book". The blend inherits some elements of the structure of every space: from the first space it adopts "nature", "researcher" and the activity of this researcher - "research"; from the second one it takes the roles of "book" and "reader", as well as the reader's activity - "reading". The selectivity of the reflection causes the fact that the blend acquires a new property "understandable, easy to research", which cannot be found in one of these original spaces, as it is assumed that the natural phenomena are difficult to research, whereas a prototypical book is not an object of research, it is rather meant to be read and interpreted. The development of the new meaning in the given blend can be explained as follows: from the space of "book" the link between the action and result is inherited ("to read the book and to understand its content"); whereas form the space of "nature" the link "to research the natural phenomena and to understand the nature's structure" is adopted. In the structure of the blend there is "nature", "researcher" and "book", though the "researcher" takes the part of "reader", and "nature" acts as "book" performing the appropriate actions, goals and results.

Analyzing metaphor in the context of the conceptual integration theory, it is necessary to define several crucial differences between this very theory and the theory of conceptual metaphor by G. Lakoff and M. Johnson. According to the latter theory, the process of metaphorization is based on the interaction between two structures of knowledge - the cognitive structure of the "source" (source domain) and the cognitive structure of the "target" (target domain), when one object or phenomenon is reconsidered in terms of another object or phenomenon due to their common characteristics. The stable relations between the cognitive structures of "source" and "target" are regarded as conceptual metaphors [2]. However, in the theory of conceptual integration, metaphor is represented as the interaction of mental spaces "here and now" which differ from the conceptual field as they are created immediately in the process of the discourse development and have the form of a scenario of the definite situation. Therefore, they are classified as temporal constructions, though some gradually integrated mental spaces may become common and usual blends.

In the theory of conceptual metaphor, there is a postulate of "unidirectional metaphorical mapping" according to which there is a unidirectional link between the source and the target and it allows interpreting more abstract things in the terms of more specific and 
structured entities. However, this principle cannot explain all the real situations $[14,15,16]$. Among such contradictory examples, the following utterance can be analyzed:

I found Burns, absorbed, silent, abstracted from all round her by the companionship of a book, which she read (Bronte Ch., Jane Eyre);

He threw the book down and walked over it and went out to the cricket. And he hated books as if they were his enemies (Lawrence H.D., The Rainbow).

The first example shows the books as friends or companions, whereas in the second one the negative emotions are described because books are presented as enemies. However, in the metaphor BOOK IS A PERSON, the source of rethinking is the concept PERSON that cannot be regarded as more specific and concrete than the concept BOOK.

The unique character of the blend or its emergence can be described and explained only in the context of the theory of conceptual integration. The following example can demonstrate the development of the new meaning in the blend:

"I love reading all our favourites,"said Kari. "I can't wait to dive into Jane Austen again" (Landvik L., Angry Housewives Eating Bon Bons).

In this utterance, there are two original spaces: the space of "submerging in water" and the space of "book". From the first original space, the blend inherits the role of a "diving man" and "pool"; and from the second one it adopts the role of a "reader" and "book". As a result of selective mapping, the new feature appears in the blend "book as another environment in which a man can submerge", besides in this case it is done to get some pleasure (the utterance I can't wait shows it). This characteristic cannot be found in the original mental spaces; it appears only as a result of the integration of mental spaces during the discourse development.

It should be mentioned that the theory of conceptual integration was researched in different fields of linguistics [17, 18, 19] and education [20].

\section{Metaphorization of the concept BOOK (the target domain)}

The analysis of the examples allowed the authors of the article to define the two types of metaphorical mapping: concept BOOK as the source domain and the target domain. Though Lakoff and Johnson's terminology is used it should be mentioned that source and target domains are regarded as interacting complementing input spaces.

In the given article the target domain with the concept BOOK is analyzed. Three overlapping metaphors with this concept were defined: A BOOK IS WORLD, A BOOK IS FOOD, A BOOK IS A PERSON.

1. A BOOK IS WORLD. The content of a book creates a special world in the mind of scientists and ordinary readers, it is proved by the great number of examples demonstrating this metaphor. This blend is created due to both metaphorical and metonymical mappings. Let's consider the following example:
I always love reading about people with lives unlike mine because I get to live in their world for a while (Landvik L., Angry Housewives Eating Bon Bons).

To create this integrated blend, one generic mental space was used, in which there is a structure common for two input spaces: the subject makes a purposeful action. The blend inherits the elements of the structure of the input spaces, but not the whole scenario of the situation. The great part of the structure is inherited from the mental space "world": a human travels to the point of destination: I get to live in their world for a while. It is very interesting for him to leave his/her world and to get into another one where he/she can accept the unusual way of living. From the mental space "book", the following structure is inherited: a human reads the book and learns a lot about the life of its characters: I always love reading about people with lives unlike mine. Thus, the blend includes the integrated roles book-world, reader-traveler and develops its own structure. Reading a book, the reader from the mental space "book" gets into another world. While travelling, the traveler from the mental space "world" gets to know the content of the book. Consequently, the world he/she reaches is not a real one, it is his/her "inner, mental world". There is not such an attribute in the input spaces "world", "book", the development of the attribute is a manifestation of the emergent properties of the given blend.

The next blend is created on the basis of the same mental spaces, but the scenario of the situation is different:

Perhaps to Richard each opening storybook cover was an opening closet door; perhaps each bright paperback cover illustrated people who never were as if they were real (King S., The Talisman).

In the mental space "book" the reader for the first time opens the book to know about the lives of the fictional people who do not exist in the real world. The scenario of the mental space "world" reflects the situation when a person is standing before the door and when he/she opens it he/she will get into some unusual situation with unknown people. In the generic space the subject again makes a purposeful action. There are integrated roles in the blend: reader-human at the door, the cover of the book-door, characters-people who should be met. In the integrated space the common property "inner, mental world" that does not exist in the structure of the input spaces appears again.

Thus, the analyzed blends are unique, but they are the result of the integration of the mental spaces with the common structural elements (have the same roles), and they are structured by the frame READING THE BOOK. The generic space is always the same in every case of the conceptual integration, and in the blends the book content acquires the property "inner, mental world".

2. A BOOK IS FOOD. As it was mentioned above, this blend is created on the basis of the conceptual metaphor IDEAS ARE FOOD. Let us analyze the example:

It brings together Lewis the scholar, Lewis the voracious reader of anything from medieval schoolmen or Italian epic to modern science fiction, Lewis the 
Christian apologist, Lewis the Irish satirist in the savage tradition of Swift, Lewis the failed Romantic poet (The British National Corpus).

In the mental space "book", the reader reads a lot: one book after another. The mental space "food" includes the role person and the role food that he/she eats very fast and greedily (one dish after another); it is evident due to the lexemes a glutton, to devour, voracious. The generic space has a structure common for the input spaces: the subject makes some purposeful action aimed at the object. There are the integrated roles in the blend: reader-person eating the food, book-food and the integrated action read-eat greedily. The mental space "food" corresponds to the source domain of the metaphorization, but the blend will not inherit its entire structure. In the mental space "food", a person eats the food, is sated and gets all the vitamins and substances he/she needs. Therefore, the blend develops its unique structure: "the reader is sated - gets to know the content of the book". In the blended structure, the book gets the property "mental food" that is used to support some mind processes.

In the next example, the mental space "food" includes the knowledge about its eating and cooking:

Roland Smith has provided us with a fascinating and interesting book that should whet the appetite of many hill walkers and will certainly provide a wealth of useful background information when planning a walk to some of the 'Great Viewpoints' of Britain (The British National Corpus).

For the development of this blend, the mental spaces "book" and "food" are used, but the scenarios of the input spaces and blended space are unique. In the mental space "book", the author wrote an interesting book that would be useful for readers who liked hiking. In the mental space "food" the subject (let's name him the cook) cooked a very delicious dish that whetted the appetite. The generic space includes the scenario of the object's creation and usage. In the blended space, there are integrated roles: author-cook offering the book-dish and interested readers-people who want to taste the dish. The emergent properties of the blend appear again due to the inconsistency of the action and its result. The action "to write the book" leads to the result that is not planned in the input mental space: the book whets the appetite. In its turn, the cooked dish from the mental space "food" meets the readers' needs to obtain the necessary information. The integration of these incompatible elements of the input structures leads to the appearance of the feature "content of the book is mental food".

Therefore, the given blends are the results of the process of the conceptual integration of the input mental spaces "book" and "food" that develop on the basis of one of two frames READING THE BOOK or WRITING THE BOOK. The generic space is always the same and includes the subject, the action and the result. In the blended spaces the combination of the action "read the book" / "write the book" and the unexpected result "to be sated" / "to cook the dish" leads to the emergent property "content of the book is mental food".

3. A BOOK IS A PERSON. This metaphor belongs to the ontological type. These blends may include metaphorical expressions with the proper names, speech verbs, causative verbs. Let us study the example in which the book became the reason of the sharp emotional reaction:

Their book caused a storm in America last year, mainly because of inflammatory passages suggesting Japan might sell technology to the Russians in spite the United States (The British National Corpus).

This blend is complex, as three mental spaces take part in the integration process. The first mental space has the elements of the frame READING THE BOOK. In the second input space, the scenario of the transfer of the negative information can be observed. The third mental space covers the scenario of the natural phenomenon, namely, storm. In the generic space, there is a common situation in which the actions of one subject caused the negative reaction of another subject. There are integrated roles in the blend: book-person giving some information, reader-person perceiving the information, person's emotions-natural phenomena. In the blended structure the compression of cause and effect occurs; it is expressed by the fact that behind the lexical unit book there is an action: people read the book. Thus, the book plays the part of the subject and its content acquires the property "person". The action read leads to the storm that represents the emotional state in the blended space.

The new book talks of the 1936 constitution as 'a contradiction between word and deed' (The British National Corpus).

This example is a blend that is developed due to the integration of the input mental spaces "book" and "person". In the first input space there is a person reading a book. In the second input space there is a situation of oral communication, in which one subject gives the information to the other subject. In the blended space the unique emergent structure develops: the book is a talking subject, the readers are listeners, so the book content acquires the emergent property "person". There is not such property in the input space "book", and in the input space "person" structured by the situation of communication the information is transferred in the oral form in the real (not mental) world.

The studied examples show the various cases of personification representing the metaphor A BOOK IS A PERSON as a result of integration of two mental spaces "book" and "person". The mental space "book" is structured by the frame READING THE BOOK. In the blend, there is an integrated role person-book, the content of the book acquires the property "person" and the emergent structure develops, in which the oral communication or the impact of the book occurs in the inner mental world.

\section{Conclusion}

Thus, the conclusion can be drawn that in the theory by Lakoff and Johnson, the conceptual metaphor is regarded as a stable common means of rethinking some entities in terms of some other entities; whereas the theory of conceptual integration by Turner and Fauconnier treats 
the mechanism of the meaning development as a spontaneous constructive act.

The conceptual metaphors A BOOK IS WORLD and A BOOK IS A PERSON can be treated as ontological ones as due to them the book is rethought as the world or as a result of interaction with a real person. The conceptual metaphor A BOOK IS FOOD is a structural one, as it reconstructs the similarities between the process of reading the book and the processes of eating and digesting food.

The revealed conceptual metaphors where the concept BOOK is the target domain are identified with the concept properties forming its structure. Their analysis showed the metaphorical mapping applied not to the entire concept BOOK, but to its abstract layer represented by the property "content"; thus, these conceptual metaphors are the result of the metonymical mapping as well - WORLD, FOOD, PERSON mean the content of the book.

\section{References}

1. O.K. Iriskhanova, On the linguistic creative activity of a human: verbal nouns (VTII, Moscow, 2004)

2. G. Lakoff, M. Johnson, Metaphors we live by (University of Chicago Press, Chicago, 1980)

3. A.N. Baranov, Yu.N. Karaulov, Russian political metaphor (dictionary items) (The Institute of the Russian Language, Moscow, 1991)

4. V.Z. Demiankov, The structures of the knowledge representation in the language, 32-86 (1994)

5. E.S Kubryakova, Proceedings of the Russian Academy of Sciences. Series: Literature and Language 56, 22-31 (1997)

6. A.P. Chudinov, Russia in the metaphorical mirror: the cognitive study of the political metaphor (The Urals State Pedagogical University, Ekaterinburg, 2001)

7. N.D. Arutyunova, Metaphor and Discourse (Progress, Moscow, 1990)

8. O.K. Iriskhanova, Proceedings of the Russian Academy of Sciences. Series: Literature and Language 60, 44-49 (2001)

9. G. Fauconnier, Mental spaces (Cambridge University Press, Cambridge, 1985)

10. G. Fauconnier, M. Turner, Conceptual Structure, Discourse, and Language, 113-129 (1996)

11. G. Fauconnier, Language and Linguistics 6, 523-538 (2005)

12. G. Fauconnier, E. Sweetser, Spaces, World and Grammar, 1-28 (1996)

13. E.V. Rakhilina, The cognitive analysis of the substantive nouns: semantics and collocation (Russkie slovari, Moscow, 2000)

14. A.N. Baranov, Metaphors We Live By (preface), 721 (2004)

15. M. Turner, G. Fauconnier, Journal of Metaphor and Symbolic Activity 10:3, 183-204 (1995)
16. T. Rohrer, International Cognitive Linguistics Conference 95 Proceedings 2, 99-129 (1997)

17. L. Brandt, The communicative mind, 231-323 (2013)

18. E. Tarasti, Futures 84(B), 120-123 (2016)

19. K. Rataj, A. Przekoracka-Krawczyk, R. H.J.van der Lubbe, Brain research 1678, 231-244 (2018)

20. S.V. Latysheva, N.V. Shchurik, The bulletin of Kemerovo State University. Series: Philology 62, 175-178 (2015) 